\section{Resumen}

El propósito de este artículo es dar una mirada crítica a la escuela como medio de movilidad social rural, estableciendo un balance entre las expectativas creadas durante el paso por el sistema escolar y las posibilidades de concreción visualizadas por los individuos, las comunidades y sociedades rurales, destacando, al final del documento, la lectura de género. En atención a la importancia de la familia y la escuela como principales instancias de socialización, lo expuesto por padres, hijos y maestros constituye el principal insumo de análisis e interpretación. Lo dicho se deriva de la labor investigativa adelantada en dos instituciones educativas del municipio de Manizales, Caldas, que en conjunto acogen a buena parte de los estudiantes provenientes de las zonas rurales del suroccidente de la ciudad.

\section{Palabras clave}

Sociedades rurales, educación rural, jóvenes rurales, movilidad social.

\section{Abstract}

The purpose of this article is to give a critical insight to the school as a means of rural social mobility, by establishing a balance between the expectations created during the passage through the school system and the possibilities of concretion visualized by the rural individuals, communities and societies. It emphasizes the gender perspective at the end of the document. Due to the importance of family and school as main socialization instances, the methodology exposes the thoughts of parents, children and teachers and constitutes the main source of analysis and interpretation.

\section{Key words}

Rural societies, rural education, rural youth, social mobility. 


\title{
La escuela como medio de movilidad social rural: reflexiones en torno a la evidencia empírica*
}

\author{
Marlon Javier Méndez Sastoque \\ Catalina Gómez Martínez² \\ Ana María Betancourt Bustamante ${ }^{3}$
}

\section{Introducción}

Definitivamente, en países como el nuestro, tanto en escenarios urbanos como rurales, el ingreso de los hijos en el sistema educativo viene siendo internalizado como norma por parte de los padres. En condiciones de vulnerabilidad socioeconómica, la apuesta familiar por la educación como estrategia de movilidad social ascendente constituye una realidad innegable. Entendiendo la movilidad como el cambio de posición en la estructura social, donde los individuos ponen en juego sus recursos con miras al logro de un estatus determinado, la escuela hace aparición como recurso o estrategia de ascenso. En este caso, la clave está en la valorización de la escolaridad como componente de un proyecto de movilidad social ascendente: los padres se esfuerzan porque sus hijos "lleguen a ser alguien en la

\footnotetext{
* Texto recibido el 19 de septiembre de 2006, evaluado el 6 de octubre de 2006, y arbitrado el 30 de noviembre de 2006.

${ }^{1}$ Ingeniero Agrónomo. Magíster en Desarrollo y Sociología Rural. Docente adscrito al Departamento de Desarrollo Rural, Facultad de Ciencias Agropecuarias, Universidad de Caldas. marlon.mendez@ucaldas. edu.co - javmendezsas@yahoo.com.mx

${ }^{2}$ Médica Veterinaria Zootecnista. Integrante del Semillero de Investigación en Ruralidades Emergentes, Facultad de Ciencias Agropecuarias, Universidad de Caldas. ktago80@hotmail.com

${ }^{3}$ Médica Veterinaria Zootecnista. Integrante del Semillero de Investigación en Ruralidades Emergentes, Facultad de Ciencias Agropecuarias, Universidad de Caldas. anitamvz@79@hotmail.com
} 
vida", lo cual usualmente se materializa en el cambio ocupacional, esto es, en que los hijos dejen de ser agricultores o campesinos ${ }^{4}$.

Sustentado en lo anterior, el presente artículo tiene como fin dar una mirada crítica al papel de la escuela como medio de movilidad social rural, a la luz de lo expuesto por sus protagonistas: maestros, estudiantes y padres de familia, motivando tanto el cruce como el diálogo entre posturas diversas. En esta ocasión lo dicho se deriva de la investigación adelantada en dos instituciones educativas del municipio de Manizales, departamento de Caldas: el Colegio María Goretti y el Seminario Seráfico San Antonio de Padua, establecimientos que en conjunto acogen a buena parte de los estudiantes provenientes de las zonas rurales del suroccidente de la localidad, destacándose, entre éstas, la vereda Bajo Tablazo, zona tradicionalmente productora de café, en asocio con plátano y banano, hoy reconocida por su alto nivel de integración rural-urbana.

El trabajo fue desarrollado entre febrero de 2005 y mayo de 2006, en el marco de la línea de investigación Dinámicas y perspectivas de las sociedades rurales, como parte de la labor del Grupo Ceres (Centro de Estudios Rurales), Departamento de Desarrollo Rural de la Universidad de Caldas. Se contó con la colaboración de estudiantes de pregrado del programa Medicina Veterinaria y Zootecnia de la misma universidad. Los resultados expuestos se sustentan en testimonios reales citados a lo largo del documento.

El artículo se compone de cuatro apartados principales. El primero atiende al interés por explorar lo que padres y maestros esperan del paso de hijos y estudiantes por la escuela, destacando la presencia de dos grandes tendencias: la conservacionista y la transformadora. El segundo, partiendo de las expectativas y querencias expuestas por los jóvenes, en gran medida derivadas de su paso por el sistema escolar, establece un balance entre éstas y las posibilidades reales ofrecidas en el contexto específico de vida. Una vez reconocido el panorama general, el tercer apartado centra la atención en las circunstancias particulares de las jóvenes rurales, privilegiando la perspectiva de género en la comprensión de la escuela como medio de movilidad social. El artículo culmina con algunas consideraciones en torno a la necesidad de incorporar los cambios acontecidos en las sociedades rurales a la práctica escolar.

\footnotetext{
${ }^{4}$ La noción de movilidad social adoptada se acerca a la reconocida como movilidad intergeneracional, la cual compara el estatus ocupacional de los individuos entre las generaciones de los padres y los hijos. Otra noción igualmente cercana es la identificada como movilidad estructural, que ocurre cuando las personas cambian de posición en la estructura social en función de mudanzas macrosociales como el flujo de lo rural a lo urbano, situación que no sólo se refleja en la migración física del campo a la ciudad, sino también en la disminución del número de individuos dedicados a actividades agrícolas tradicionales dentro de las comunidades y sociedades rurales.
} 


\section{Lo que se espera del paso por la escuela}

Ante las dificultades que supone la vida en el campo, la escuela frecuentemente aparece como alternativa familiar de mejoramiento individual y colectivo. Dentro de la familia, la integración efectiva al sistema escolar es usualmente acogida como estrategia de superación y distinción, otorgando a la educación de los hijos el papel de punto o factor de quiebre de los ciclos de reproducción social de las condiciones de desventaja generacionalmente heredadas. Cuando lo anterior es lo que prima, en la medida que los problemas estructurales que aquejan a las sociedades rurales se mantienen o acentúan (pensemos en la violencia, la inequidad social, la invisibilización por parte de la sociedad general, por citar no más algunos), si se trata de dar cuenta de lo que se espera del paso por la escuela, con mucha insistencia lo que se anhela es el abandono del campo o, más específicamente aún, de las labores agrícolas tradicionales como fuente principal de sostenimiento individual y familiar. Al respecto, veamos lo dicho en el siguiente testimonio:

Yo les digo a mis niños que no se dediquen mucho al campo, porque quiero que ellos salgan adelante, que se dediquen a una profesión; por lo que más lucho es porque salgan adelante y no porque se dediquen de lleno a esto. Está bien que les guste, pero que sea algo como una especie de hobby, porque lo que yo quiero es que ellos salgan adelante y estudien; el estudio es lo que más les inculco yo a ellos, el estudio, y si ellos quieren estudiar algo relacionado con el campo, también los respeto y los apoyo. (Señora Luz Marina Quintero, madre de familia, Vereda Bajo Tablazo, 30 de julio de 2005).

Como podemos apreciar, la escolarización es asumida como estrategia de escape. Las generaciones precedentes confían en que, vía estudio, los niños y jóvenes rurales logren forjar proyectos de vida que vayan más allá de lo predeterminado: la vida en un contexto agrícola y rural $^{5}$, para muchos asociada a pobreza y atraso, observación que, sin ser única, es de alta frecuencia en los escenarios rurales donde predominan condiciones de vulnerabilidad socioeconómica:

A mí sí me gustaría que ellas hicieran algo diferente, que estudien, que salgan adelante, porque cada vez la situación es más difícil. Entonces, por ejemplo, es mejor que tengan su buen empleo, porque el campo no se los puede brindar. Yo lo que quiero es ayudarle a las niñas con el estudio, porque

\footnotetext{
${ }^{5}$ En este caso, cuando se alude al contexto de vida agrícola y rural, se evoca la noción más tradicional, esto es, aquella que asocia lo rural a la territorización de lo agrícola, asumiendo las sociedades rurales como autosuficientes, autárquicas y cerradas, en oposición al modo de vida urbano. Esto con el propósito de favorecer la inmediata identificación de cambios en la ruralidad tradicional, principalmente asociados a la atenuación de los límites entre el campo y la ciudad, el reconocimiento de la articulación funcional entre lo rural y lo urbano, la incursión ocupacional de los sujetos rurales en escenarios no agrícolas y urbanos, así como la ruptura del localismo en las relaciones interpersonales.
} 
espero que no se queden como me quedé yo; por eso les digo mucho a ellas que valoren el estudio y que salgan adelante. (Señora Nury Moscoso, madre de familia, Vereda Bajo Tablazo, 6 de julio de 2005).

Con certeza, la visión del campo como escenario de pocas oportunidades para las generaciones actuales y venideras ocupa un lugar importante en el imaginario de muchos pobladores rurales, situación que estimula el trazo de estrategias de movilidad ascendente. Mas, si acogemos lo anterior como guía de acción, ¿de qué manera la escuela disipa o refuerza dicha perspectiva?

Definitivamente, la respuesta a esta pregunta nos ubica en medio de la contradicción. Mientras por un lado domina la tendencia conservacionista, por el otro lo hace la transformadora. La primera ubica la escuela como escenario protagónico de socialización, destacando su papel en la transmisión de saberes, normas y valores agrícolas y rurales; compartiendo dicho rol con la familia, en cuanto institución garante de la transmisión del acervo y la tradición de una generación a otra. Al respecto Bonfil (2001) señala que la educación y la escuela actúan como nicho e instrumento de resistencia cultural, aportando elementos para la reafirmación de las identidades rurales, así como para el planteamiento de proyectos integrales, locales y alternativos que refuercen dicha identidad. Según esta misma autora, en las sociedades rurales la educación ha de permitir recuperar la memoria y las costumbres que están cayendo en desuso, acercar los saberes del conocimiento escolarizado a las necesidades y prácticas de la ruralidad, así como documentar y fundamentar la divergencia entre lo propio y lo extraño. En tal noción prima el ánimo conservador y legitimador de la tradición heredada.

No obstante, aunque ésta sea una intención loable, la realidad de la vida cotidiana nos enfrenta a situaciones que introducen duda, a la vez que desequilibran las orientaciones predispuestas:

Nosotros vivimos muy preocupados porque al colegio le tenemos que dar una modalidad distinta, que puede ser, por ejemplo, Escuela Nueva, buscando que los jóvenes se queden en el campo y continúen aquí sus estudios; pero, también hay que decirlo, apenas estamos creando el modelo. Estos muchachos, en la época que viven, merecen que nos acerquemos más a ellos y a sus padres, buscando el diálogo y la concertación, y así mirar y definir qué rumbo les vamos a dar, porque este mundo está cambiando aceleradamente. El muchacho de hace cinco años no es el muchacho de hoy, ni sus expectativas, ni sus necesidades son las mismas; por esto es que estamos buscando cómo responderles de la mejor forma.

Nosotros quisiéramos que ellos no se fueran de acá, que aprendieran a trabajar la tierra, que siguieran produciendo lo básico, lo necesario para la alimentación, ya que en la ciudad todo lo tienen que comprar; pero ellos dicen que así se van a quedar toda la vida pobres, que no van a progresar si se quedan acá. 
Para que se quedaran habría que mentalizarlos mucho, tendríamos que hablar bastante con ellos, con los papás, hacer muchos conversatorios para que vayan cambiando de idea. Sin embargo, sabemos que éste es un trabajo que requiere paciencia, porque ellos tienen muy sembrada la idea de que el campo apenas les permite subsistir; lo asocian a pobreza y a mínimo progreso. Entonces, la tarea es hacerles pensar que el campo es su futuro, que hay que volver al campo, que hay que estar en el campo, y más cuando nos ubicamos en una región rural, que además está muy cerca de la ciudad. Éste es un trabajo que tenemos que hacer muy bien, incluso apoyándonos en otras personas que les hablen y aconsejen, para así lograr que cambien de opinión. (Sacerdote Javier González García, director del Colegio Seráfico, Manizales, 28 de junio de 2005).

Como podemos apreciar, las rupturas con la tradición no se hacen esperar. Definitivamente, la realidad y el orden heredados son puestos en duda por las últimas generaciones; la legitimidad históricamente construida empieza a perder peso en forma paulatina, sobre todo entre los más jóvenes. En esta vía, tal como plantean Berger y Luckmann (1979), "el problema de la legitimación surge cuando las objetivaciones del orden institucional deben transmitirse de generación en generación” (p. 135). En el proceso de reproducción social, el carácter autoevidente de las instituciones (la racionalidad agrícola y rural, para nuestro caso específico) ya no puede mantenerse por los propios recuerdos y habituaciones del individuo. La unidad histórica se restringe, por lo que en muchas ocasiones hay que restaurarla acudiendo al convencimiento. En estos casos, la solución está en resaltar los elementos sobresalientes de la tradición, sobreponiéndolos a las ideas que los niegan o resignifican, asunto que se torna corresponsabilidad de la escuela.

En este sentido, que las nuevas generaciones se identifiquen con la agricultura, la tierra, el campo y la naturaleza, en cuanto comportamiento esperado, legitimado y coherente no es siempre fácil de alcanzar. En esta tónica, como señala Méndez (2005a), la aparición de universos simbólicos alternativos representa una amenaza en la medida en que su existencia demuestra empíricamente la dudabilidad del orden institucionalizado. A pesar de la fuerza de la tradición, en la práctica es frecuente la ocurrencia irregular de cambios en los hábitos, las ideas y costumbres que desestabilizan lo históricamente acentuado, circunstancia a la que la propia escuela contribuye, mediante la exposición de los jóvenes a nuevos hábitos y códigos culturales, dándole cabida a la segunda directriz: la tendencia transformadora.

Como señala Durston (1997),

La educación invariablemente expone al joven a nuevas ideas diferentes de las tradicionales tanto de la visión de mundo como de valores éticos y derechos. Modifica su concepción del mundo, lo que lleva frecuentemente al con- 
flicto con instancias sociales importantes del medio en que los jóvenes viven. (Impactos de la educación en las relaciones entre el o la joven y su hogar, 2).

Sin lugar a dudas, en las actuales sociedades rurales, la escuela cumple un papel fundamental: servir de ventana al mundo exterior. Además de favorecer la adquisición de herramientas que mejoran su desempeño productivo, así como su capacidad de aporte a la economía familiar, la escuela directa o indirectamente promueve y facilita su apertura física y mental a escenarios distintos al submundo habitual. En esta misma línea, como sugiere Dirven (2000),

La educación formal no sólo aumenta los conocimientos básicos de lectoescritura y operaciones matemáticas, sino que también influencia la actitud frente a la vida y la capacidad de organización y manejo del tiempo. Estas características y el currículo escolar mismo, así como las características específicas de la etapa juvenil, hacen que este grupo etario tenga una actitud más abierta hacia las innovaciones y los mayores riesgos que las acompañan, que las generaciones anteriores (p. 6).

Definitivamente, la escuela contribuye a ampliar los ángulos de mira, coadyuvando, si es preciso, a resignificar la propia existencia y a imaginar nuevos escenarios de vida, que luego serán traducidos en objetivos reales y alcanzables. En la vida cotidiana, el hecho de compartir un mismo escenario con docentes y otros estudiantes con orígenes e historias distintas a la propia, estimula al joven a ver más allá de su ámbito tradicional de existencia. En la práctica, más allá de los encuentros convencionales en el aula, lo que ocurre es una transposición de submundos. La oportunidad de reconocer al otro en su historia particular favorece la aparición de puntos de encuentro y desencuentro: profesores de origen rural que viven permanentemente en la ciudad y laboran en el campo; profesores de origen rural que accedieron a la educación superior a pesar de las dificultades por ellos mismos relatadas; profesores de origen citadino interesados en la vida en el campo, que añoran poder vivir en un ambiente campestre; compañeros de clase citadinos con aspiraciones ajenas a la actividad agrícola; compañeros orgullosos de su condición rural y compañeros que la niegan o esconden.

Por otro lado, la relación con el conocimiento universal también amplía la noción de mundo. En la medida en que la escuela favorece la exploración disciplinar, la gama de opciones vocacionales crece: jóvenes rurales apasionados por la química o jóvenes rurales apasionados por las artes y las letras constituyen un ejemplo de lo dicho; pues, a riesgo de sobresimplificar la discusión sostenida, ¿acaso los jóvenes rurales sólo deben saber e interesarse por aquello asociado a la producción agropecuaria? Como puede inferirse del siguiente testimonio, la escuela cumple una misión liberadora, en la medida en que invita a cruzar los límites de lo inmediato o conocido: 


\begin{abstract}
Aquí, todos los profesores permanentemente les están dando a los estudiantes información sobre todas las áreas de formación. Cada uno busca establecer contactos con el mundo exterior, presentándoles opciones sobre lo que pueden hacer en cada área, que luego puedan ser vistas como alternativas de vida. (Señora Aleida Quintero, directora del Colegio María Goretti, Manizales, 30 de junio de 2005).
\end{abstract}

Como podemos apreciar, en contraposición a la postura conservacionista, con este último enfoque lo que se espera del paso por la escuela es la adquisición de habilidades para el cambio. Si lo agrícola no se vislumbra como posibilidad o querencia por parte de los jóvenes del campo, lo que resta es prepararlos para un tránsito oneroso, dando lugar a lo urbano o a lo no agrícola como escenarios de acogida previsibles. Pues, ante un entorno cambiante donde las nuevas generaciones conciben su propia existencia más allá de lo tradicionalmente impuesto y donde la interacción y el intercambio con el exterior están a la orden del día, ¿por qué insistir en igualar educación rural a la mera formación para el ejercicio efectivo de actividades netamente agrícolas?, o, en casos donde es plenamente reconocido que el acceso a los bienes de producción representa un obstáculo familiarmente insuperable, ¿por qué insistir en la actividad agrícola como principal o única vía de vida y de generación de ingresos? (Méndez, 2005b).

Sin duda, la escuela como fuente de apertura a otras o nuevas posibilidades desempeña un papel destacado en aras del cambio sugerido. Mas, si el cambio se deriva de concretar aquellas alternativas, en términos prácticos, ¿qué caminos se vislumbran para los jóvenes rurales? De esto nos ocuparemos en el siguiente apartado.

\title{
Encuentros y desencuentros entre lo probable, lo deseable y lo posible
}

Retomando las tendencias anteriormente desarrolladas, y en coincidencia con lo expuesto por Guaraná (2004), las percepciones sobre los posibles caminos a seguir por los jóvenes rurales fluctúan entre quedarse o partir. Cuando opera lo primero, a quienes permanecen les es otorgado el papel de agentes resguardadores del orden, siendo ellos los primeros llamados a rescatar los valores, las prácticas y costumbres heredadas. Cuando tiene lugar lo segundo, la sensación de pérdida reina. Previendo esta última alternativa, la acción defensiva no tarda en aparecer. Una vez reconocido el riesgo, desde la escuela se actúa impidiendo que los jóvenes completen su designio: "La migración del campo a la ciudad y el consecuente fin del mundo rural, en especial del trabajo familiar" (p. 5). No obstante, si se hace una lectura comparada, lo que para los conservacionistas significa la debacle rural, para quienes deciden migrar hacerlo connota, por lo menos en el discurso, mejorar sus condiciones y posibilidades de vida. Pero, independientemente de la 
vía elegida, si nos remitimos a la experiencia real y cotidiana, ¿cuál es el contexto en el que se da la elección?

Definitivamente, la opción por permanecer en el campo, migrar a la ciudad u optar por ocupaciones no agrícolas o urbanas depende de varias circunstancias anexas. $\mathrm{Al}$ respecto, veamos lo expuesto por el siguiente testimonio:

Para muchos de estos jóvenes el futuro está en el campo. Así no sea lo que quieren, es a lo que terminan dedicándose, bien sea porque cuentan con la tierra o porque sus padres tienen la posibilidad de ayudarlos a conseguir trabajo en eso; igual porque es algo que hace parte de la cultura y la herencia familiar recibida. Aunque esto esté cambiando para las últimas generaciones, no está abolido del todo. Sin embargo, en el campo los muchachos crecen con unos altos niveles de desesperanza; ellos creen que la única solución que tienen en el mundo es irse a coger café, pero es un oficio que poco les gusta.

Entre los muchachos hay algunos que son más acomedidos y aceptan con mayor facilidad el trabajo que les toca; pero esto no significa que lo hagan con mucho agrado, es más por obligación que por vocación. Pero, a pesar de todo, son muchachos que tienen capacidad de lucha. Aunque sus expectativas sean altas, ellos son conscientes de que no tienen las posibilidades para llegar a una universidad; ellos se ven en desventaja frente al estudiante de la ciudad. Ellos son conscientes de que el salario de un jornalero que tiene que ver por 6 o 7 hijos, o el de una madre que tiene que velar por estos 6 o 7 hijos, no alcanza para sostenerlos en una universidad; por eso, la mayoría piensa más en carreras tecnológicas, técnicas o en una formación del SENA. Son escasos los que piensan que pueden llegar a la universidad; para ellos eso es muy distante.

Aquí hay que destacar un problema importante, es que aunque se insista en la formación agropecuaria, las familias de los muchachos no son propietarias. Sus padres son personas que trabajan en fincas como agregados, como trabajadores; entonces fácilmente se les acaba el trabajo y tienen que irse para otras partes, y esto los descuadra muchísimo. Por eso muchos jóvenes y padres, aunque son del campo, no han querido adoptar el modelo agropecuario en los estudios, como sería lo adecuado, siendo ésta una región rural. Los muchachos dicen: ¿Para qué si no tenemos finca?, ¿’para qué si no tenemos posibilidades de ser propietarios?, entonces, mejor un bachillerato académico, y después nos vamos a la ciudad a ver qué pasa con nosotros. (Señora Aleida Quintero, directora del Colegio María Goretti, Manizales, 30 de junio de 2005). 
Ciertamente, al momento de optar por cualquier camino, las circunstancias asociadas al ámbito particular familiar pueden tornarse motivantes o restrictivas. Mientras quien se queda lo hace buscando potenciar lo heredado, quien parte ambiciona procurar medios propios de subsistencia. No obstante, en muchas ocasiones, el sistema educativo no repara en estas distinciones. Como lo expresa el anterior testimonio, en casos específicos, la educación rural con énfasis agropecuario se oferta en entornos caracterizados por la prevalencia de condiciones familiares de limitado acceso a los factores de producción. En esta línea, la carencia de tierra y capital en el presente (así como la mínima expectativa de acceso en el futuro a estos mismos recursos) motiva a explorar caminos distintos al tradicional. Ante esta dinámica, para muchos padres, el estudio constituye el principal valor inculcado y heredado a los hijos, aunque, a diferencia de quien tiene un patrimonio heredable, sus expectativas están puestas en el abandono del campo, esto es, en preparar a los jóvenes para la salida:

Yo quiero que mi hija estudie; yo sí le he dicho a ella que no se quede allí terminando sólo el bachillerato, que piense en algo que a ella le guste, que piense en una carrera y uno hace el esfuerzo por darle esa carrera. Lo importante es que ella se vaya abriendo otro camino. (Madre de Magda Valencia, Vereda Bajo Tablazo, 14 de julio de 2005).

Sin lugar a dudas, la confianza depositada en la escuela como medio de movilidad social es una realidad. En las circunstancias descritas, ascender en la jerarquía del sistema educativo significa ascender a niveles más complejos de conocimiento y a posiciones más altas en la estructura ocupacional. No obstante, a pesar de las intenciones señaladas, las posibilidades de dar continuidad al escalonamiento escolar más allá de la educación media suelen ser limitadas, hecho que induce tanto a padres como a hijos y maestros a explorar otras opciones formativas. $\mathrm{Al}$ respecto, veamos lo planteado en el siguiente testimonio:

Muchos de los muchachos, en el caso de los hombres, piensan en pagar servicio: me voy para el ejército, yo para qué estudio si me voy para el ejército; visiones que son resultado de la desesperanza. La única opción es irse a prestar servicio militar o irse a la policía, y para eso ellos no necesitan ir a la universidad. Como padre, cada quien quiere para su hijo lo mejor; si no pueden costearle la universidad, ven para ellos otras opciones de vida; entonces comienza: mïjo, afánese para que entre al SENA o a Ingecómputo o a estudiar auxiliar de enfermería, porque es hasta donde ellos ven que les pueden ayudar. Muchos manifiestan: yo quisiera darle universidad a mi hïo, pero ven que la opción más cercana es esto. (Señora Aleida Quintero, directora del Colegio María Goretti, Manizales, 30 de junio de 2005). 
Definitivamente, como menciona Bourdieu (2003), "el desfase entre las aspiraciones que el sistema escolar estimula y las oportunidades que realmente garantiza constituye el fundamento de la decepción” (p. 148). En esta vía, las expectativas y los deseos, aunque en algún momento puedan superar las posibilidades reales, con el tiempo suelen ajustarse a los límites previstos:

Quiero ser policía de carreteras; también me gustaría estudiar algo de sistemas, casarme, tener dos hijos y tener una casa en el barrio Palermo. Espero que mi familia me apoye en todo esto. (Juan David, 18 años, estudiante de $11^{\circ}$, Colegio María Goretti, Manizales, 16 de junio de 2005).

Quiero ser suboficial de la policía; mis padres me apoyan. Me gustaría fundar una institución para niños pobres y ayudar a la gente que lo necesita, contando con la ayuda de mis padres y mi futuro esposo con el que tendré una niña. Quiero vivir en una finca muy grande con mi familia y tener muchos animales. (Marcela, 17 años, estudiante de 11², Colegio Seráfico, 15 de junio de 2005).

Mis metas son trabajar como educadora con la Fundación Luker ${ }^{6}$, trabajar con el Comité de Cafeteros, con la Licorera de Caldas, pues, como esas empresas están vinculadas con la escuela y nos están ofreciendo cien puestos para bachiller, y yo aspiro a quedarme con un puesto de esos, y mientras trabajo voy a estudiar sicología. (Lorena, 17 años, estudiante de $11^{\circ}$, Colegio María Goretti, julio 6 de 2005).

Como podemos apreciar, en cuanto deseo ocupacional, las opciones no agrícolas y urbanas ganan cada vez más espacio en los imaginarios y las realidades de los jóvenes del campo. No obstante, en la medida en que las circunstancias familiares son disímiles, hay quienes sí ven en el campo alternativas hacia el futuro, reafirmando lo rural como línea heredada y por seguir:

Quiero graduarme de veterinario. Yo sé que es muy difícil, pero si lo logro, me gustaría irme para un lugar que me sirva, aunque mis padres no están de acuerdo con que esté lejos de ellos. Espero poder lograr todos mis sueños. (Jorge, 18 años, estudiante de $11^{\circ}$, Colegio María Goretti, 16 de junio de 2005).

Ante esta dualidad es necesario reconocer que las propias transformaciones del entorno rural sugieren superar el acentuado sesgo agrícola. Como podemos apreciar

\footnotetext{
${ }^{6}$ La Fundación Luker es una institución privada, sin ánimo de lucro, constituida en 1994, con el propósito fundamental de gestionar y apoyar proyectos para beneficiar la comunidad de estratos bajos de la ciudad de Manizales. Concentra la mayor parte de sus esfuerzos de gestión, apoyo y cofinanciación en proyectos en áreas de recreación y educación, en los que la población beneficiaria sea principalmente niños y jóvenes de bajos recursos económicos.
} 
en las intenciones de los jóvenes, no en contadas ocasiones sus miradas traspasan lo netamente agropecuario; tal hecho coincide con una tendencia actual: en las áreas rurales, el número de habitantes dedicados a actividades económicas y productivas no necesariamente ligadas a la producción animal o de cultivos es cada vez mayor.

A título de ilustración, en el lugar de estudio, Vereda Bajo Tablazo, según reportes de Méndez et al. (2006), de las 156 familias que allí habitan, el 65,4\% obtiene sus recursos de actividades no agrícolas, el 12,8\% de labores netamente agrícolas (cultivo de café y plátano, principalmente) y el 21,8\% de una combinación entre agrícolas y no agrícolas. De acuerdo con este mismo estudio, entre las principales actividades no agrícolas se destacan las asociadas al comercio formal e informal, a la industria y a los servicios auxiliares, generales y domésticos.

Situaciones como la anterior sugieren poner en entredicho la efectividad y conveniencia de los modelos educativos rurales centrados en la formación agropecuaria, pues, si nos preguntamos de qué vive la gente del campo, a lo mejor, la respuesta esperada: de la actividad agropecuaria, no será la principal. Ante estas realidades, sin negar la producción agrícola como posibilidad futura para los jóvenes rurales, desde la perspectiva educativa y formativa resulta urgente examinar otros caminos. Como menciona Durston (1998) al aludir a la compatibilidad de ambas alternativas, "a la juventud rural le debe ser otorgada la doble posibilidad de aprender a ser empresarios agrícolas productivos y, al mismo tiempo, desarrollar destrezas que puedan ser demandadas en forma de trabajo asalariado (aunque también independiente) tanto agrícola como no agrícola" (p. 24), asunto sobre el cual la escuela tiene o tendría mucho que hacer.

Con todo, es necesario considerar que, en términos de escolaridad, las exigencias de la demanda laboral en el sector no agrícola superan las del agrícola. En circunstancias de baja escolaridad rural, las posibilidades de incursión en espacios no agrícolas y urbanos se restringen a aquellas que requieren baja o mínima calificación. Al no actuar sobre dicha situación, de ser expertos o potencialmente expertos en producción agrícola, al transitar hacia lo no agrícola, los individuos rurales pasan o pasarían a ser considerados "ignorantes" o "descalificados funcionales", poniéndose en evidencia su alta vulnerabilidad. Dicha circunstancia exige ampliar la cobertura educativa rural, pensando en la formación de sujetos capacitados para actuar en escenarios tanto agrícolas como no agrícolas, dando cabida a la exploración y opción vocacional más allá de lo tradicional.

Mas, si se desestimula lo agrícola como opción ocupacional y de vida, sobreponiendo lo no agrícola y urbano como deseo y posibilidad real para las actuales y nuevas generaciones del campo, en términos socioeconómicos y culturales, ¿acaso nos encontraríamos presenciando e impulsando el fin de la tradición rural?

Sin lugar a dudas, cualquier cambio genera temores y tensiones. La ruralidad de hoy no es la misma de antes. La disminución paulatina de las fronteras entre 
el campo y la ciudad, la integración cultural entre sociedades rurales y urbanas, así como los cambios ocurridos en la sociedad general, constituyen algunos de los factores de mudanza. Retomando lo dicho por Martín-Barbero (1999), como nunca a lo largo de la cultura universal, culturas tradicionales como las campesinas se ven cada vez más involucradas en procesos de interacción con otras culturas de la nación y del mundo. Trasladando lo dicho a nuestra temática de estudio, podríamos decir que hoy día lo rural no se conserva en su pureza. Los procesos de hibridación cultural han dado paulatina cabida a expresiones otrora distinguibles como extrañas o foráneas, situación a la que han contribuido la escuela y los procesos migratorios:

Definitivamente hay dos tipos de niños: los niños que económicamente pueden estar yendo a Manizales, niños que tienen costumbres muy citadinas, y los que por factores económicos o bien por problemas de transporte, porque viven en vereditas donde es más difícil transportarse, no puede estar yendo a la ciudad. Entonces, aunque no a todos, a los niños sí se les pegan las costumbres citadinas, pero yo diría que se trata de un pequeño porcentaje. Diría que es lógico que en estas circunstancias se mezclen las costumbres citadinas con las rurales, pero lo preocupante es que a veces resulta una mezcla un poquito peligrosa, porque los niños no saben dónde están, si son citadinos o si son rurales. Si están acá en la vereda, son rurales, pero si van a la ciudad, tienen que acomodarse a que son citadinos. Yo digo que esto es de cierta forma normal, el mundo de hoy está globalizado, así las personas salgan poco, hay costumbres de fuera que se le van pegando. (Señora Aleida Quintero, directora del Colegio María Goretti, Manizales, 30 de junio de 2005).

Como ya se ha sugerido de distintas maneras, la escuela, bien sea implícita o tangiblemente, permite transgredir los límites impuestos por la tradición, dando lugar a la ampliación cultural. Explícitamente, en los casos en que ingresar en el colegio impulsa a los jóvenes a entrar en contacto con maestros y pares urbanos, así como con lugares más allá del plano veredal o local, los referentes de socialización cambian, corriéndose incluso el riesgo de desidentificación con el ámbito de origen, vía contrastación o presión social. Al respecto, veamos lo ilustrado por el siguiente testimonio:

Yo siempre he dicho que el Bajo Tablazo es un híbrido, que no es ni ciudad ni campo, que tiene la cultura citadina muy cercana a la cultura campesina; entonces se empiezan a establecer comparaciones entre la niña y el joven de la ciudad y el joven y la niña del campo; para ellos es normal decirle al otro: no muestre la montañerada, justamente por ese híbrido. En las veredas es normal que los muchachos digan: estuve cogiendo café, estuve desyerbando, 
estuve trayendo leña. Pero aquí en el Tablazo a veces las cosas son distintas. Guando el muchacho dice: estuve en el polideportivo, estuve en el fútbol, estuve caminando, lo hace con orgullo. Sin embargo, cuando menciona que estuvo trabajando en la tarde, o que trabaja o trabajó en las labores del campo, los otros se mofan de él: jah, está cogiendo café! (Señora Aleida Quintero, directora del Colegio María Goretti, Manizales, 30 de junio de 2005).

Como podemos observar, la hibridación cultural señalada acarrea ciertos riesgos. No obstante, aunque llegue a causar desconcierto, es necesario asumirla como una realidad próxima e ineludible. Como sugiere Carneiro (1998), "las transformaciones en las comunidades rurales debidas a la intensificación de los intercambios con el mundo urbano (personales, simbólicos, materiales, etc.) no resultan necesariamente en la pérdida de los rasgos distintivos de un sistema social y cultural" (p. 60). Por tanto, no se trata de un proceso inexorable de descaracterización de los núcleos rurales, mas sí de una reestructuración a partir de la incorporación de nuevos componentes económicos, culturales y sociales que amplían y complejizan el acervo disponible. En esta misma tónica, la migración del campo a la ciudad, usualmente asumida como enemigo por combatir, habría de asumirse como una posibilidad más. Como señala Durston (1998):

Si lo que nos motiva es fundamentalmente el bienestar de los jóvenes rurales, tenemos que reconocer que en muchas situaciones la migración es positiva para ellos, particularmente en dos casos extremos: en primer lugar, en las comunidades más pobres atrapadas en una fase incipiente de transición demográfica ocupacional, donde se ha agotado la productividad de la tierra y ésta ha sido fragmentada por herencia a varios hijos; donde la mera supervivencia exige que algunos de los hijos migren, mientras otros se quedan con la tierra. En contraste, en comunidades más modernas donde los padres han hecho una inversión en la educación de sus hijos, la migración de estos jóvenes no puede ser frenada, pues las oportunidades de mayores niveles de instrucción no pueden ser adquiridas localmente. En ambos casos, parece justo que los programas provean capacitación que posibilite la opción real de buscar una mejor vida en otra parte (p. 25).

Las posibilidades abiertas por la escolarización pueden motivar procesos migratorios. En la medida en que las posibilidades de desempeño laboral llegan a ser restringidas en los ámbitos rurales, los escenarios urbanos constituyen una alternativa apreciable, circunstancia que ha de ser considerada por el propio sistema escolar, pues, si esta es una opción tangible de movilidad social, ¿qué tanto prepara la escuela para la partida?, o más específicamente aún, ¿qué tanto se enseña en las escuelas rurales para hacer con posterioridad frente al mundo no agrícola o urbano? 
Como se ha hecho notar hasta ahora, la decisión de quedarse o partir involucra elementos de orden social, cultural y económico, que van muy de la mano de las tendencias globales, caracterizadas por la inserción de lo local en lo global. En este contexto, los cambios acontecidos en la sociedad general no dejan de permear los mundos tradicionales. En la medida que las normas, los valores y las costumbres se someten al rigor de los cambios de época, las sociedades más conservadoras incorporan a su haber toda una serie de ganancias y transformaciones sociales, ajustándose a los nuevos tiempos.

Ganancias como las asociadas al reconocimiento efectivo de las particularidades étnicas, raciales y de preferencias sexuales, el respeto a la diferencia y la diversidad social y cultural, la libertad de credo, el desarrollo de la libre personalidad, la libertad de elección, así como la atención a las demandas específicas de género, están a la orden del día en el ámbito global, permeando en distintos grados a las sociedades más tradicionales. Desde esta perspectiva, lo deseable y lo posible se encuentran ahora liberados de ciertas ataduras sociales. De esta manera, los individuos y grupos tradicionalmente vulnerados perciben en el contexto actual alternativas más claras de reivindicación.

Mas, si esto es así, ubicados de nuevo en los escenarios rurales desde donde muchos jóvenes crean sus proyectos de vida, asumiendo a las mujeres como grupo social y tradicionalmente vulnerable, en términos de género y movilidad social, ¿qué tanto se ha avanzado en superar la discriminación y la subordinación femenina y cuál ha sido el rol de la escuela al respecto? De esto nos ocuparemos en el siguiente apartado.

\section{Género y movilidad social rural}

Como lo ilustra el siguiente testimonio, a pesar de sus menores niveles de escolaridad, desde la perspectiva de género, y avizorando para ellas un futuro distinto, las madres son un apoyo esencial para las hijas en sus esfuerzos por educarse:

A nosotras no nos decían nada sobre el estudio: las mujeres en la casa y los hombres en el campo; era como una obligación trabajar para aprender, y nosotras nos teníamos que quedar en la casa para aprender para cuando tuviéramos marido. No nos gustaba el campo. Mi mamá sí se interesaba porque estudiáramos; ella nos enseñaba muchas cosas y fuimos e hicimos la primaria, pero no más; porque para conseguir marido y quedarse en la casa, estudiar más era botar la plata. A mí me gustaría que mis hijas estudiaran, y después de que estén preparadas y sean casadas, ellas mismas puedan llevar una obligación; entonces, si llegan a tener un mal marido, lo puedan dejar y no tener que depender de él. Es que lo más triste es eso, uno tener que depender de un hombre para todo: ¡Ay no!, qué pesar ellas tener que esperar que les dé hasta para un pasaje para poder ir a Manizales; eso es muy triste, 
pero todavía hay mucha gente esperando eso. (Señora Rubiela González, Vereda La Violeta, 17 de julio de 2005).

No hay duda de que en los hogares rurales cada vez hay más mujeres con horizontes distintos al de sus predecesoras. Ubicadas en los tiempos de hoy, las reivindicaciones sociales históricas, como las referidas al cambio de la situación de la mujer y su papel en la sociedad, también tienen cabida en los escenarios rurales. Las condiciones de subordinación, discriminación y exclusión, otrora asumidas como típicas, hoy pierden legitimidad, sin que esto signifique su total abolición. Indiscutiblemente, el acceso femenino al sistema escolar ha contribuido a lograr lo señalado. Vía apertura mental, la escuela ha favorecido la posibilidad de contrastar y deshacer mitos e imaginarios acerca de lo que significa ser mujer. Al respecto, veamos lo expuesto en el siguiente testimonio:

El hecho de que en los hogares pueda haber 5 o 6 hijos de padres diferentes afecta mucho a los muchachos, y crea niveles de rebeldía y juzgamiento hacia esa madre, porque ella ha permitido tener hijos de padres diferentes. Muchos de los muchachos no conocen el papá. Esto se presenta porque es muy común en la mujer campesina conseguir un hombre para que le ayude a sostener los hijos. Vive un año con él y tiene un hijo más de él, pero se cansa, se aburre o el hombre le dio mala vida o no le respondió como debía responderle, entonces lo deja y se consigue otro; eso es común en el sector rural, porque las mujeres se ven en desventaja si no tienen un hombre al lado. Sin embargo, las adolescentes hoy están pensando distinto; ya ellas piensan que el fin no es tener hijos simplemente por tener, sino que todo esto hace parte de un proyecto de vida; ellas vienen en ese proceso de transformación, y desde aquí contribuimos a que eso sea así. (Señora Aleida Quintero, directora del Colegio María Goretti, Manizales, 30 de junio de 2005).

Interpretando lo anterior, podemos plantear que, en términos del cambio y la movilidad social, las transformaciones aludidas están relacionadas con la autonomía que aspira a lograrse frente a la autoridad masculina y el modelo androcrático dominante. Considerando el rol de la escuela en la promoción de dichos cambios, Bonfil (2001) plantea que a mayores niveles de instrucción femeninos se presentan cambios socioculturales, económicos y demográficos importantes, entre los que señala los siguientes: a) retraso en la edad de la primera unión y de inicio de la vida reproductiva; b) mayores índices de escolarización en las siguientes generaciones; c) mejores niveles de nutrición y desarrollo de la salud; d) periodos intergenésicos más prolongados, y e) mayores niveles de ingresos. No obstante, a pesar de los avances factibles, la autora es muy cauta al señalar lo siguiente: "En la medida en que los núcleos rurales están inmersos en condiciones estructurales de desventaja, estos beneficios sólo alcanzan a casos individuales y no pueden hacerse extensivos 
para el conjunto de la población femenina en entornos rurales" (p. 542). Esta observación la compartimos plenamente, sobre todo cuando centramos la atención en la invisibilidad otorgada a la mujer en cuanto sujeto productivo en la actividad agropecuaria.

Como sugiere Ospina (1998), muchas de las mujeres rurales, además del trabajo en el escenario doméstico, están efectivamente vinculadas a la economía de mercado en todas las etapas de las cadenas productivas (producción, transformación, comercialización y consumo), así como al mercado laboral extrapredial. No obstante, las condiciones en que se da esa participación aún no son equitativas con las de los hombres, en atención a las siguientes circunstancias: a) no se reconocen ni valoran tanto la importancia de las mujeres en la esfera propiamente productiva, como la compleja red de interacciones e interdependencias que se dan entre los trabajos reproductivos, los propiamente domésticos y los directamente orientados a la producción para el mercado, b) no tienen fácil acceso a los activos y recursos productivos, aumentando así de manera significativa sus costos de transacción; c) son discriminadas en el mercado laboral, y d) no son sujetas de derechos plenos en relación con los recursos y beneficios del desarrollo que ellas directamente contribuyen a generar.

Para el caso específico del Bajo Tablazo, de acuerdo con lo reportado por Méndez et al. (2006), del total de trabajadores activos, el 31,5\% corresponde a población femenina. De este porcentaje; es decir, del total de mujeres reconocidas como trabajadoras en su condición de aportantes directas a la economía familiar, el 75\% está dedicado a actividades no agrícolas, 20,5\% a actividades netamente agrícolas y el 4,5\% a actividades pluriactivas, correspondiendo las dedicadas a actividades exclusivamente agrícolas a mujeres jefes de hogar vinculadas como asalariadas a los cultivos de flores y follajes recientemente instaurados en la zona. Como podemos apreciar, la mujer apenas logra ser reconocida como trabajadora cuando opta por ocupaciones no agrícolas, en la mayoría de ocasiones realizadas fuera del hogar, o cuando se vincula como asalariada agropecuaria, ejerciendo sus labores extrapredialmente. En la mayoría de ocasiones, su labor es desconocida, o mejor enmascarada, bajo la figura de trabajo doméstico, en cumplimiento de su rol de ama de casa. En estas circunstancias, su vital aporte a la reproducción, la producción para el autoconsumo y producción para el mercado es vagamente valorado, situación que constituye una de las principales causas de ruptura de las mujeres de las últimas generaciones con el orden y la autoridad familiar que invisibilizan su existencia y aporte. Pero, desde el punto de vista curricular, ¿qué tanto es considerado esto en la escuela?

$\mathrm{Al}$ respecto, asumiendo una postura crítica, Ospina (1998) comparte lo siguiente:

En una lectura de la sociedad desde la perspectiva de género, no es suficiente que las mujeres hayan alcanzado niveles de matrícula equiparables a los de los hombres cuando, dentro de las precarias condiciones de la edu- 
cación rural en Colombia, la institución educativa y el aparato educativo a su servicio - con un 70\% de docentes mujeres en el sector rural-continúan reproduciendo valores que sustentan la reproducción por sexos de los roles de género al interior de la economía doméstica campesina, independientemente de los avances que al respecto tenga el conjunto de la sociedad, sobre los cuales se soportan y reproducen la discriminación y la subordinación contra las mujeres (p. 28).

Innegablemente, resulta imprescindible avanzar en el reconocimiento de la mujer rural como sujeto económicamente activo, vinculado al mercado de trabajo tanto agrícola como no agrícola, venciendo el acentuado sesgo de género. Potenciar sus capacidades en ambos campos, deshaciendo la idea que la asocia y limita a los oficios netamente domésticos o auxiliares, constituye el principal reto, en aras de superar la marcada y sostenida segregación social femenina, rasgo aún sobresaliente en las sociedades rurales.

Es evidente que cualquier tradición suele ser altamente conservadora, así como cuidadosa al momento de afinar sus mecanismos de legitimación y protección ante lo nuevo o distinto. No obstante, la capacidad de los sujetos para fraguar y potenciar cambios, asumida como principal fuerza liberadora y emancipatoria, también está siempre presente. Para nuestro caso específico de estudio, luchar contra el sesgo de género constituye el principal reto por asumir. Así, aunque a veces de manera acrítica, las culturas tradicionales, incluyendo por supuesto a las rurales, en tiempos de homogeneización económica y cultural, lleguen a sobrevalorarse y sobreprotegerse, es necesario poner en evidencia los riesgos de reproducir algunos de sus más acentuados rasgos. Sin duda, en cumplimiento de nuestro papel de docentes rurales o para la ruralidad, vale la pena mirarnos hacia dentro; es decir, pensar y reflexionar nuestra acción en contexto, llegando, si es el caso, a hacer visible lo invisible en nuestra propia práctica cotidiana; pues, ante el frecuente llamado a conservar el orden y las tradiciones, después de una lectura crítica y comprometida, desde nuestra labor formativa, ¿qué preservar y qué procurar transmutar?

\section{Consideraciones finales}

Después del recorrido hasta aquí realizado, podemos llegar a la siguiente conclusión: la escuela como medio de distinción y movilidad social rural ha de habilitar a los sujetos no sólo para la reproducción, sino también para la producción y la emancipación social. Definitivamente, la formación de sujetos pensantes constituye uno de los principales aportes del sistema escolar al desarrollo rural. Además de instruir, la escuela educa y habilita para volver críticamente sobre la tradición, lo cual ha de asumirse como un paso fundamental para la valoración, el reforzamiento y la transformación del legado recibido. 
Asociado a lo anterior, aunque cueste trabajo aceptarlo, en términos generales, la carga nostálgica que a veces acompaña a los esquemas de educación rural puede estar más en la mente de los docentes y administradores que en las prácticas cotidianas de los sujetos y las comunidades que acompañan. En las actuales condiciones, la hibridación cultural es lo que marca la pauta. En esta medida, salvaguardar a los niños y jóvenes rurales de cualquier tipo de contaminación exterior, otrora lineamiento de conservación cultural, a la fija restringe posibilidades de ser. En esta tónica, retomando la cada vez más tenue distinción entre lo rural y lo urbano, podemos plantear que en el proceso de articulación existirían dos posibilidades generales: a) que el núcleo rural sucumba a las presiones o a los intereses externos, dejando de ser lo que es, y b) que se consolide y se nutra la identidad local a partir de su encuentro con lo otro o distinto. En el primer caso, es evidente que las perturbaciones sobre la tradición pueden resultar destructivas, al punto de abolir los rasgos que hacen a las sociedades rurales distintas del resto de la sociedad; eso sí, sin que esto quiera decir que la totalidad de elementos que integran la tradición merezcan ser exaltados, reproducidos, así como resguardados de cualquier alteración. Pues, como ya se mencionó en el apartado anterior, hay algunos valores en las sociedades rurales que valdría la pena transmutar. En el segundo caso, la reapropiación de elementos de la cultura rural a partir de una relectura posibilitada por el contacto con lo urbano u otros escenarios contrastantes puede resultar beneficiosa. En esta línea, la interacción no se traduce necesariamente en la destrucción de la cultura propia, mas sí en la apertura a nuevos códigos que pueden incorporarse al acervo particular, posturas que, en conjunto, nos llevan a replantear lo rural dentro de un proceso dinámico en continua construcción, del cual la escuela ha de tomar parte.

En esta misma vía, y en aras de situarnos como parte del cambio, como sugieren Jentsch y Burnett (2000), los cuestionamientos sobre el devenir de los jóvenes rurales deben ser menos sobre si se quedan o se van, y más sobre las experiencias por ellos vividas y los procesos que acompañan la toma de decisiones. Como se ha tratado de esbozar aquí, el análisis ha de recaer sobre los cambios en el valor simbólico o material de la herencia, en las relaciones con la autoridad paterna, familiar y comunal, y principalmente en las acciones de los jóvenes antes y a partir de dichas transformaciones; por ejemplo, en las ocurridas en relación con la posibilidad de heredar o adquirir bienes productivos, el acceso a la educación, los entornos urbanos y las relaciones de género, entre otros elementos.

De igual forma, resulta pertinente reconocer que hoy más que nunca, ni la familia ni la escuela constituyen los únicos nichos de socialización. En la actualidad, el efecto de los medios de comunicación sobre la definición del ser y el querer ser complejiza cualquier observación al respecto, situación de la cual las sociedades rurales no están para nada al margen. Por otro lado, es igualmente importante señalar que a pesar de los esfuerzos realizados desde los planos familiar y educa- 
tivo, el peso de lo estructural sobre el devenir de las sociedades rurales aún sigue ocupando un lugar protagónico. Mientras perdure la guerra físicamente concentrada en los territorios rurales, así como sus causas intactas, la incertidumbre seguirá primando en nuestros campos. Con esto se quiere resaltar que una buena experiencia escolar no es suficiente para la generación de cambios positivos en las sociedades rurales. La escuela es un elemento primordial, aunque no único, en el proceso de movilidad y transformación social. No obstante, su aporte es uno de los más valiosos, en la medida en que se ejerce directamente sobre los sujetos, es decir, sobre el sustento empírico de cualquier transformación: los hombres y mujeres constructores de realidad.

Finalmente, retomando la emotividad de la práctica investigativa, queremos que éste sea un motivo para felicitar y reconocer la labor de las maestras y los maestros rurales: sujetos llamados a acompañar y liderar las sendas del desarrollo rural de nuestra patria y nuestra América Latina.

\section{Bibliografía}

Berger, P. y Luckmann, T. (1979). La construcción social de la realidad. Buenos Aires: Amorrortu Editores.

BonfiL, P. (2001). ¿Estudiar para qué? Mercados de trabajo y opciones de bienestar para los jóvenes del medio rural. La educación como desventaja acumulada. En: Pieck, E. (Ed.), Los jóvenes y el trabajo. La educación frente a la exclusión social (pp. 527-549). México: Universidad Iberoamericana.

Bourdieu, P. (2003). Cuestiones de Sociología. Madrid: Editorial Istmo.

Carneiro, M. (1998). Ruralidade: novas identidades em construção. Revista Estúdios, Sociedade e Agricultura, 11(2), 52-75.

Dirven, M. (2000). La contribución de lo rural al desarrollo y el potencial de la juventud. Ponencia presentada en el Foro
Electrónico Consulta Interamericana sobre Juventudes Rurales: Jóvenes en la Nueva Ruralidad. Extraído el 28 de noviembre de 2005, desde el sitio Web del IICA: http://www.iica.org.uy/ PONENCIA-DIRVEN.dOC

Durston, J. (1997, agosto). Fuventud rural en Brasily México. Reduciendo la invisibilidad. Ponencia presentada en el XX Congreso de la Asociación Latinoamericana de Sociología. São Paulo.

(1998). Juventud y desarrollo rural: marco conceptual y contextual. Santiago de Chile: Cepal.

Guaraná, E. (2004, agosto). Sonhos, desejos e a "realidade": herança, educação e trabalho de jovens rurais da Baixada Fluminense. Ponencia presentada en el Primer Simposio Internacional de Juventud Brasileña. Río de Janeiro. 
Jentsch, B. y Burnett, J. (2000, julio). Experiences of rural youth in the risk society: the transition from education to employment. Ponencia presentada en el X Congreso Mundial de Sociología Rural. Rio de Janeiro.

Martín-Barbero, J. (1999). Las transformaciones del mapa cultural: una visión desde América Latina. Revista Andaluza de Comunicación, 2, 7-22.

MéNDEz, M. (2005a). Contradicciones, complementariedad e hibridación en las relaciones entre lo rural y lo urbano [versión electrónica]. Revista Mad, 13, 1-30. (2005b). Los retos de la educación formal ante una nueva y cambiante noción de lo rural. Pedagogía y Saberes, 22, 41-47.

SÁnchez, G. y Bedoya, J. (2006). Ruralidad, pluriactividad y trabajo rural no agrícola: reflexiones en torno a la evidencia empírica. Manuscrito enviado para publicación.

Ospina, R. (1998). Para empoderar a las mujeres rurales. Bogotá: IICA-Tercer Mundo Editores. 